\title{
ANALYSIS OF SURFACE CHEMICAL CONTAMINATION ON EX-SERVICE INDUSTRIAL GAS TURBINE COMPONENTS
}

\author{
"Steven Feng ${ }^{1}$, Barbara Shollock ${ }^{1}$, Roger C. Reed ${ }^{2}$, Mary P. Ryan ${ }^{1 "}$ \\ "1 Imperial College London; Department of Materials, Exhibition Road; London, SW7 2AZ, UK" \\ "2University of Birmingham; Metallurgy and Materials Science, School of Engineering, Edgbaston; Birmingham, B15 2TT, UK"
}

Keywords: "Thermal Barrier Coatings, Surface Deposits, Iron Oxide, Industrial Gas Turbine"

\begin{abstract}
The origin of surface discoloration on Thermal Barrier Coatings (TBCs) of land-based industrial gas turbine hot gas path vanes has been investigated. Three ex-service row one (R1) vanes have been examined. Dense black colour deposits were observed on the pressure side leading edge and trailing edge, whereas red and brown deposits were present on the pressure side surface. Energy dispersive spectroscopy (EDS) analyses reveal a significant amount of iron oxide present with smaller amount of calcium, magnesium, aluminium, and silicon. X-ray diffraction revealed that the surface film was mixture of hematite $\left(\mathrm{Fe}_{2} \mathrm{O}_{3}\right)$ and magnetite $\left(\mathrm{Fe}_{3} \mathrm{O}_{4}\right)$ phases. This research aims to characterise these surface oxides with the aim of understanding the TBC surface condition whilst in service.
\end{abstract}

\section{Introduction}

Inlet gas temperatures for modern gas turbine engines are reaching $1650^{\circ} \mathrm{C}$ or higher for their turbine sections and the first and second stage vanes and blades are now fully protected by state-of-the-art thermal barrier coatings (TBCs) [1]. The TBCs protect the underlying substrate from the hot gas while the intermediate bond coat provides additional oxidation resistance. Since land-based industrial gas turbines (IGTs) operate isothermally and continuously for thousands of hours before making any stop for maintenance, TBC lifetime estimation for coated components is critical. Failure of a turbine blade whilst in service would lead to considerable economical loss. It is critical to understand all the surface and interfacial parameters, such as the behaviour of any deposits as well as their relationship with the surface temperature and oxygen partial pressure. Understanding the formation and distribution of surface deposits would provide valuable information about the regional TBC surface condition during service. Such knowledge could help provide data for TBC life estimation.

A modern combined cycle gas turbine (CCGT) power plant has reported heavy surface contamination on the TBC coated nozzle guide vanes and blades. Since the particular CCGT has an advance air filter system, the contaminants were mostly debris from internal sources such as compressor blades. Chemical deposits found were most significant on the R1 vanes which revealed various bands of color on the surface of the TBCs. Three serviced-retrieved R1 nozzle guide vanes were examined. Among these vanes, various levels of TBC surface discoloration have been confirmed. The distribution and variation of these deposits show marked differences along cooling channels within some of the single vanes indicating that the deposit (or the deposition process) is strongly affected by temperature. Additionally there are notable differences from one vane to another suggesting that each vane had experienced a slightly different exposure to the deposit or a temperature or $\mathrm{O}_{2}$ profile whilst in service.

\section{Experimental Procedures}

Three R1 vanes were removed from a Siemens V94.3 gas turbine after $\sim 14,000$ equivalent operating hours. This machine consists of silo combustors feeding into the R1 vanes with a turbine inlet temperature of $\sim 1160{ }^{\circ} \mathrm{C}$. There is a swirl in the gas as it enters the row 1 vanes meaning that the gas is hotter for some vanes than others. The amount of discolouration on the vanes varies and three vanes were selected showing marked differences in their surface discolouration. Vane $\mathrm{A}, \mathrm{B}$, and $\mathrm{C}$ were chosen to represent the variation of possible temperature profiles based on their geometric arrangement in-plane.

In order to have a better understanding of the deposit chemistry

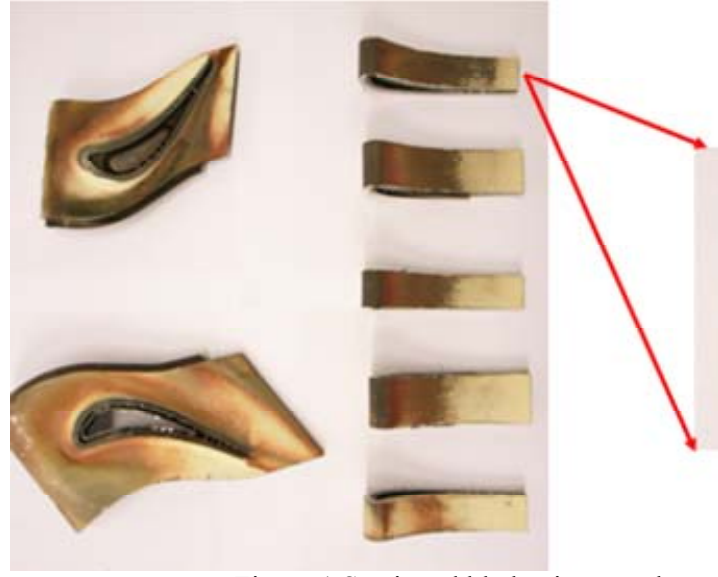

\section{Position4 Position3 Position1}

Figure 1 Sectioned blade pieces and areas selected for SEM examinations 
and morphology, a range of techniques were used. Surface and cross-sectional scanning electron microscopy (SEM) were conducted on five selected positions across the pressure side of the discoloured nozzle guide vane. Figure 1 illustrates position 1 to 5 on a sectioned vane piece. This particular vane piece has 4 different colours of deposits: black, light brown, dark brown, and red. SEM examinations were performed on sectioned vane pieces with various TBC discolorations. Field-emission-gun scanning electron microscopy (FEGSEM; LEO Gemini) was used to examine the surface and cross-section of sectioned pieces. The in lens secondary electron mode was employed and images were taken at $5 \mathrm{KV}$ with a working distance of $7 \mathrm{~mm}$. For crosssectional images of the surface deposits, backscattered electron mode (BSE) was selected to show the phase contrast within the deposit layer. Oxford Instruments ISIS EDS was used to perform surface and cross-sectional mappings to determine the elemental composition and distribution of the deposits. X-ray diffraction was conducted on discoloured TBC surfaces using Philips PW 1710 diffractometer with $\mathrm{Ni}$ filtered $\mathrm{Cu} \mathrm{K} \alpha$ radiation. A step size of $0.04^{\circ}$ and scan step time of $30 \mathrm{~s}$ per step size was set for all XRD spectra.

\section{Results and Discussion}

\section{$\underline{\text { Visual Inspection }}$}

Pressure side images of Vanes A, B, and C are shown in Figure 2. The TBC coatings on these vanes were prepared by air plasma spraying method. The TBC surface discoloration as monitored by visual inspection varies dramatically between the vanes: Vane A had most of its surface covered (approx $75 \%$ surface area) by the deposit, Vane B 50\% and Vane C had the least (approx $35 \%$ ). The discolored areas reveal dark / light brown, red and black deposits on all three vanes. Dark / light brown deposits tend to cover most of the area on the pressure side. Red deposits can only be seen near the pressure side leading edge. Lastly, black deposits are observed on both pressure side leading edge and trailing edge. Vane C, which reveals the highest ratio of black deposit has TBC coating spallation observed at its pressure side leading edge, as shown in Figure 3.

The vane platforms were also examined and have a notable discoloration pattern. One of the interesting observations is that the distribution of red deposits tends to align with the path of cooling air from the trailing edge as shown in Figure 4. Unlike the hot gas exits from the combustor, this internal cooling air contains much higher oxygen content (close to atmospheric $\mathrm{pO}_{2}$ ).
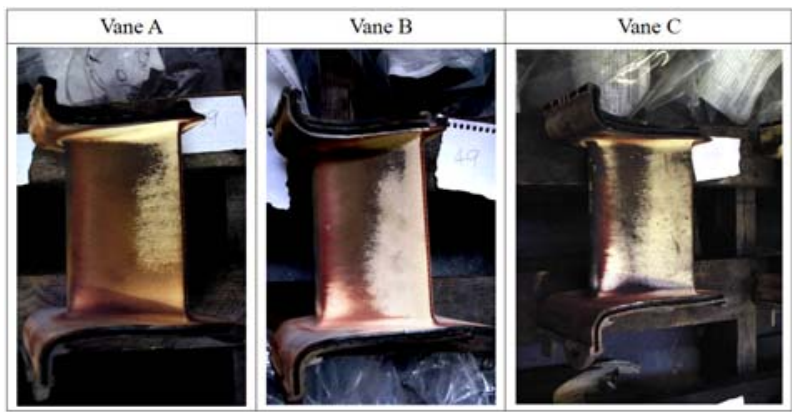

Figure 2 Pressure side surface images of Vane A, B, and C

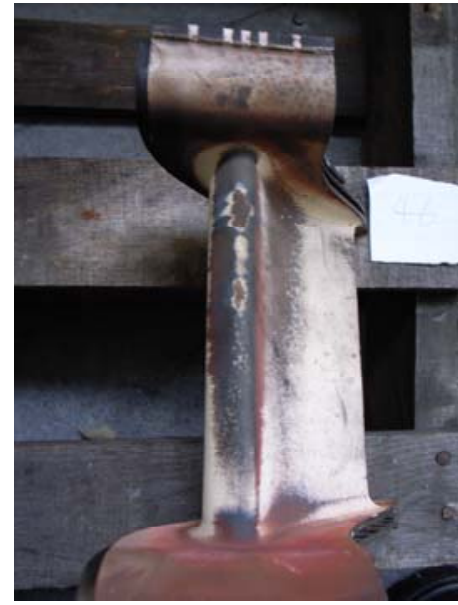

Figure 3 Spallation of Vane $\mathrm{C}$ on the pressure side leading edge

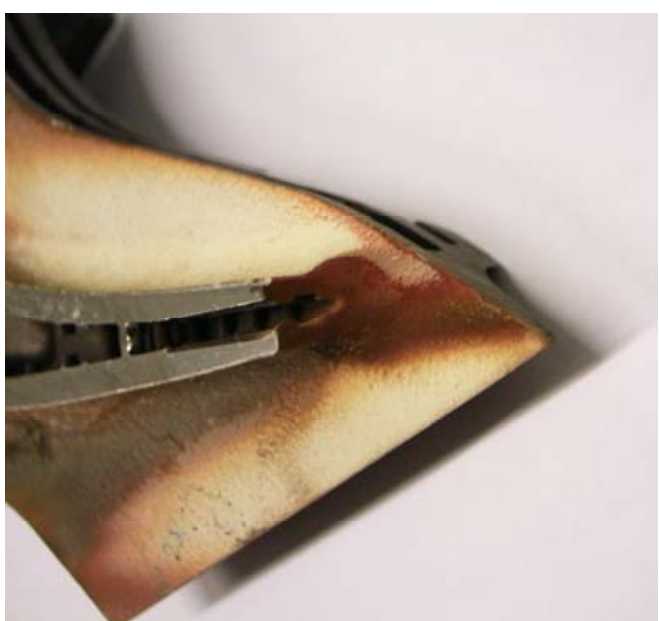

Figure 4 Red deposit near the cooling duct

\section{$\underline{\text { Microstructural Examination }}$}

\section{Surface Analysis:}

Surface SEM imaging on the deposit has revealed several surface morphologies across the pressure side vane surface. The most commonly observed surface structures were granular and flagstone-like plates (Figure 5 and Figure 6). The size of the granular particles was relatively uniform ranging from 2 to $4 \mu \mathrm{m}$. The flagstone-like plates on the other hand had much more variation in size with typical plate sizes ranging from 3 to $10 \mu \mathrm{m}$. For the larger plates, a horizontal ridged surface was also observed. Consolidated region (Figure 7) and needle-like structures (Figure 8) were also observed; however, these microstructural features occupied only a minor fraction of the total surface area analyzed.

In general, regions with brighter surface deposits (light brown, bright red) tend to have uniform granular macrostructures. Regions with darker surface deposits (dark brown, black) reveal flagstone-like plates. The black deposits in particular, have almost the complete surface dominated by large plates whereas dark brown deposits have mixtures of granular and plate surfaces. 


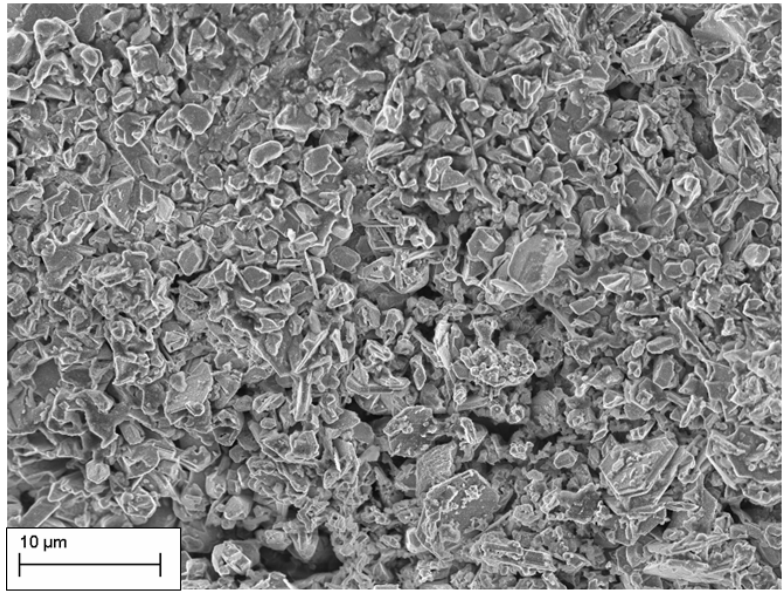

Figure 5 Granular structures on the commonly observed on the lighter colour deposit surface

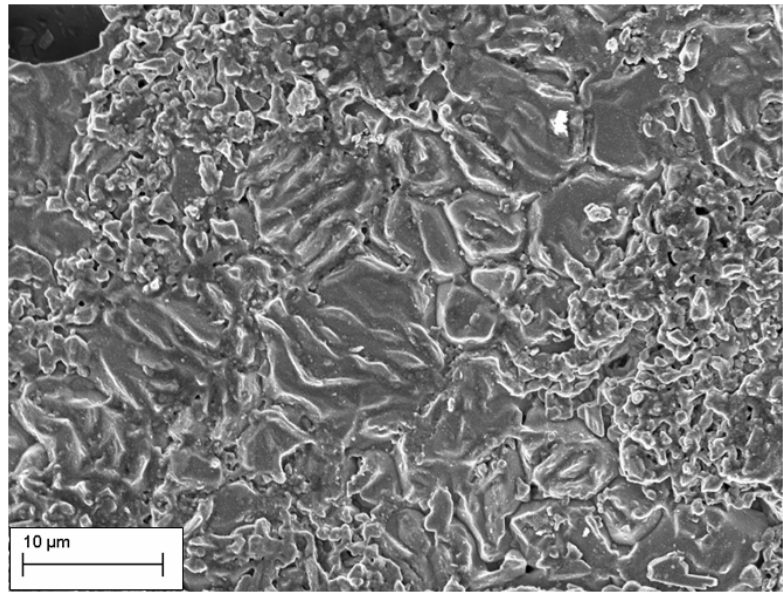

Figure 6 Flagstone-like plates commonly observed on darker deposit surface

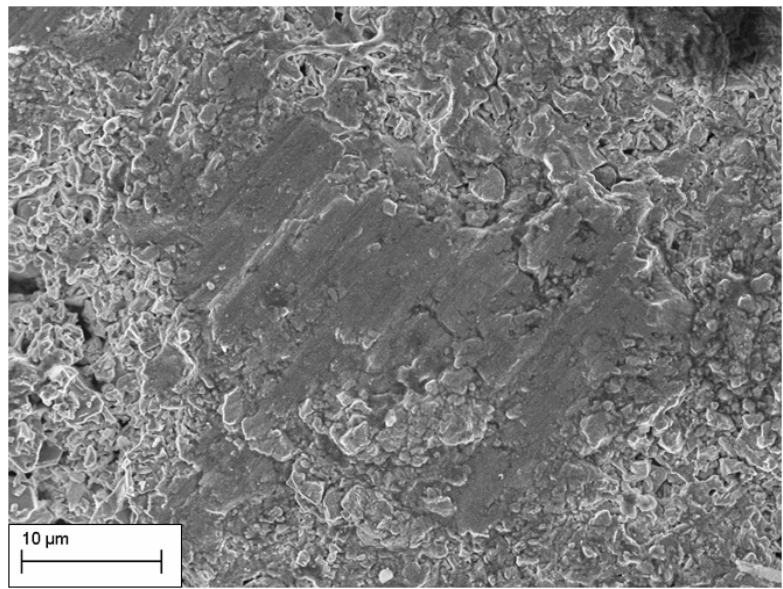

Figure 7 Large area of consolidated region on top of granular layer

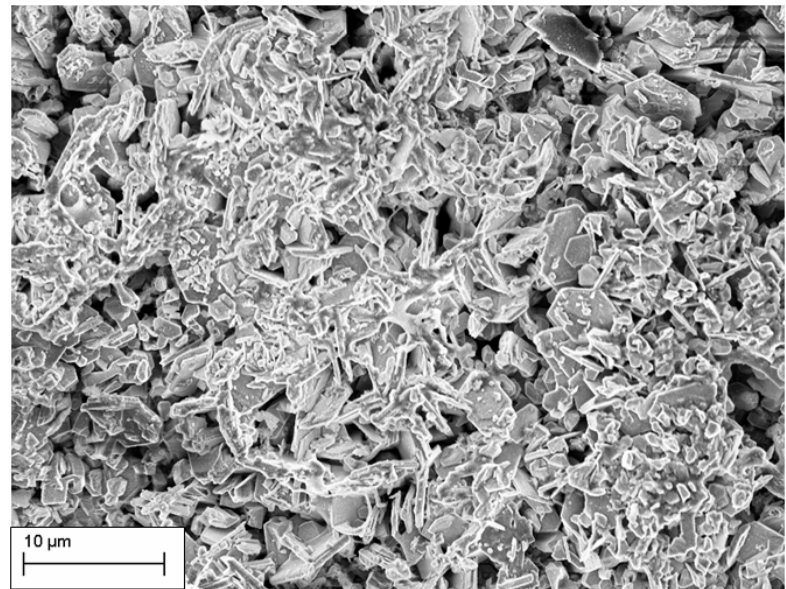

Figure 8 Needle-like structure surface observed in lighter colour deposits

\section{Energy Dispersive Spectroscopy}

In terms of chemical composition, surface EDS mappings have detected iron with traces of calcium $(\sim 5$ at $\%)$, magnesium $(\sim 1$ at $\%)$, aluminium $(\sim 5 \mathrm{at} \%)$, and silicon $(\sim 1$ at $\%)$. The calcium, magnesium, aluminium, and silicon, are primarily sand and dust particles which pass through the filter system from outside. It was first suspected that these elements are forming the form of CMAS (calcium-magnesium-alumino-silicate) which is commonly reported in aerospace and most land-based gas turbine applications [2, 3]; however, the EDS results from Figure 9 and 10 does not provide enough evidence to this assumption. This particular CCGT avoids environmental attacks such as CMAS through equipping with efficient air filters which block most external impurities. Iron oxide, which is the major contaminant in this case, is suspected to come from the wear debris of the steel components within the gas turbine, particularly from the compressor stages.

Figure 9 shows the EDS mapping of a granular surface from a light brown coloured surface. Results indicate signals of calcium, magnesium, aluminium, and silicon in combination with much larger iron signals. The flagstone surface structure shows high intensity of iron and oxygen. Figure 10 is the EDS mapping of the flagstone plate from a region covered by black deposit. Signals of calcium, magnesium, aluminium, and silicon come from the gaps and openings of the flagstone-like plates. It is therefore believed the flagstone plates are iron oxide and granular particles are either a mixed $\mathrm{Fe}$-oxides or multiphase grains. 

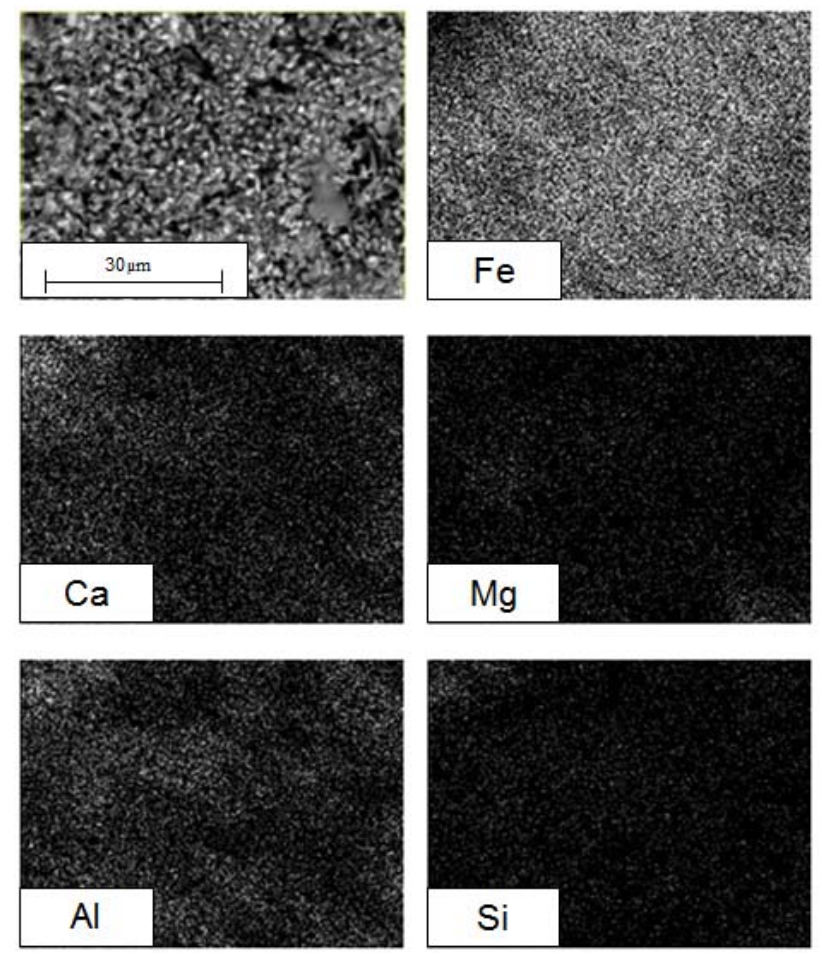

Figure 9 EDS Mapping on granular surface reveals the chemical composition and distribution of $\mathrm{Fe}, \mathrm{Ca}, \mathrm{Mg}, \mathrm{Al}$, and $\mathrm{Si}$
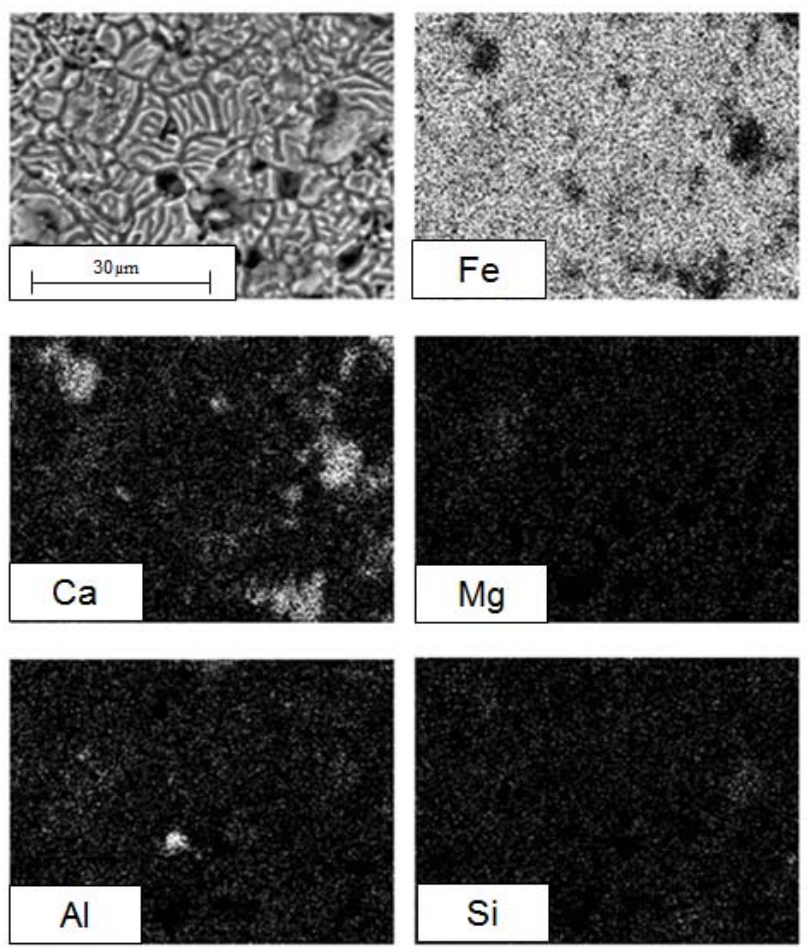

Figure 10 EDS Mapping on Flagstone plate surface reveals mostly iron on the surface

\section{Cross-sectional Analyses}

Cross-sectional analyses have been conducted on the various deposits. Figure 11 and Figure 12 show the light brown and red deposits respectively. A large amount of voids were observed within these deposits. The back scattered electron mode (BSE) images also revealed multiple phases within the deposit layer such that a dense, high atomic number layer exists at the outer most layer of the deposit. This outer layer is not uniform in thickness and has a granular structure. It is confirmed from the surface SEM that granular structure dominates the surfaces of lighter colour deposits (light brown and red). These cross-section images revealed that the granular layer is only a thin layer on the surface while a compact layer lies underneath. The granular layer shows high BSE - contrast, indicating the presence of high atomic number elements.

Figure 13 and Figure 14 show the cross-section SEM images of dark colour deposits (black and dark brown). From these microstructures, the dark colour deposits are clearly more consolidated than those light colour deposits. The denser deposit layer reveals less porosity which suggests a sintering effect may have taken place at these sites. Multiple phases are also identified from these SEM images. Recall from the surface EDS mapping of flagstone-like plates, calcium and aluminium signals were also identified. Signals of these elements came from the calcium and aluminium containing layer right under the flagstone-like plate surface; however, this denser phase is only a thin layer $(\sim 5 \mu \mathrm{m})$ and is not representative of the bulk of the deposit.

Growth of the thermally grown oxide (TGO) can also be measured from the cross-sectional SEM images. The thickness of the TGO layer under the black deposit surface (Figure 15) is considerably thicker than that of light brown deposit site (Figure 16). The growth rate of the TGO between a TBC and a MCrAlY bond coat is dependent upon temperature $[4,5]$. Formation of TGO therefore provides evidence about the relative temperature experienced at these two sites. i.e. these data imply that the black deposit covered area had experienced a relatively higher temperature than the region with light brown deposit. Further analytical work will be performed to quantify this.

\section{Energy Dispersive Spectroscopy}

Cross-sectional EDS analysis examined the chemical composition and distribution of the contamination deposit. EDS mapping again reveals heavy iron content $(\sim 30$ at $\%)$ with minor trace of calcium $(\sim 2$ at $\%)$ and aluminium $(\sim 5$ at $\%)$. Figure 17 shows the EDS mapping of a light brown deposit site. Calcium and aluminium were observed near the surface and the deposit / YSZ interface, whereas the bulk of the deposit is primarily iron oxides. The calcium and aluminium appear to be inhomogeneous, suggesting the existence of two difference compounds. As comparison, EDS mapping of dark brown deposit is shown in Figure 18. Minor calcium and aluminium signals were again detected from these dense regions. In the study of other environmental degradation, yttria extraction was reported. Stott et al have shown that in the case of CMAS attack, yttria content could be extracted from the YSZ top coat $[6,7,8]$. However, as for this particular iron oxide deposits, EDS mappings reveals no sign of yttria extraction (at least within the sensitivity of this measurement). 


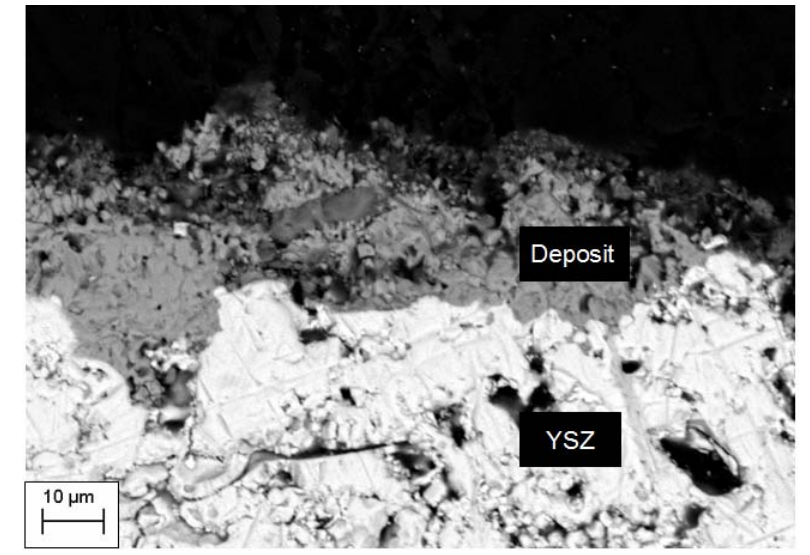

Figure 11 Cross-sectional SEM of light brown deposit

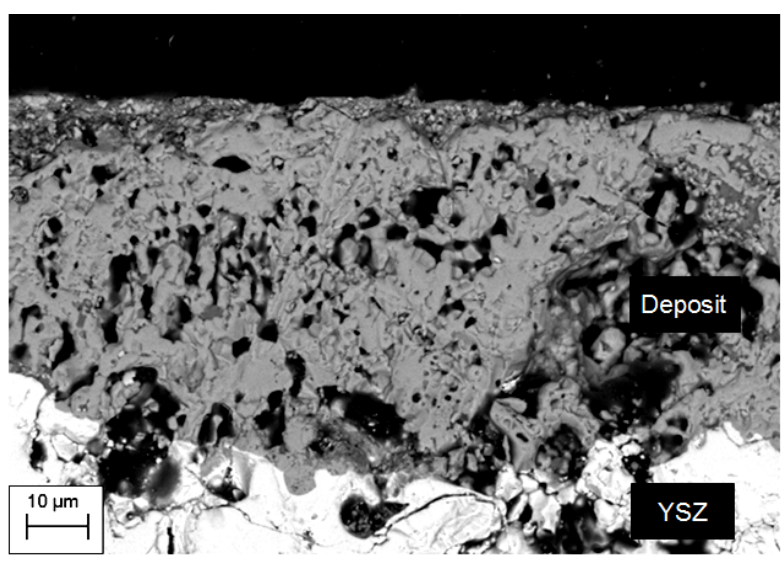

Figure 12 Cross-sectional SEM of red deposit

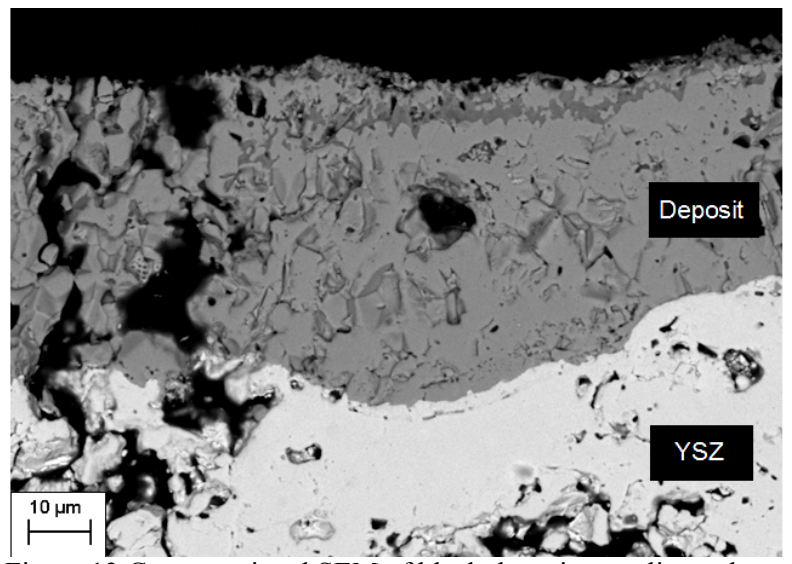

Figure 13 Cross-sectional SEM of black deposit revealing a dense layer near the surface

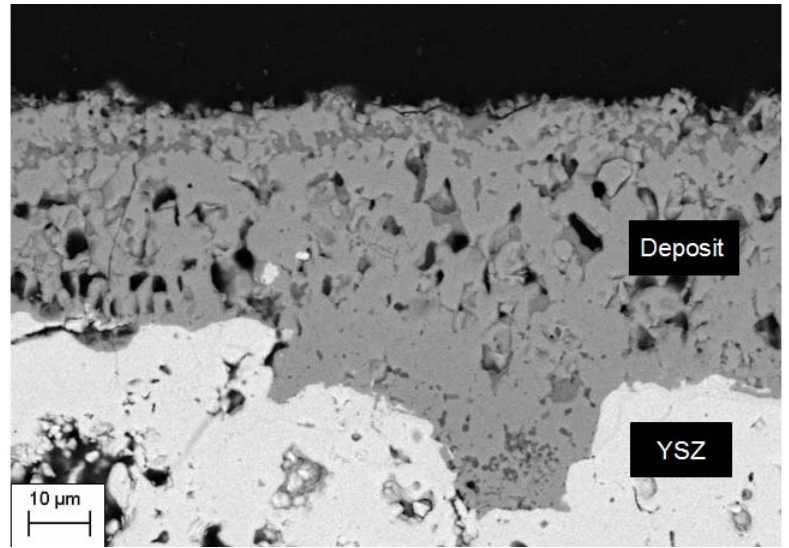

Figure 14 Cross-sectional SEM of dark brown deposit revealing a dense layer near the surface

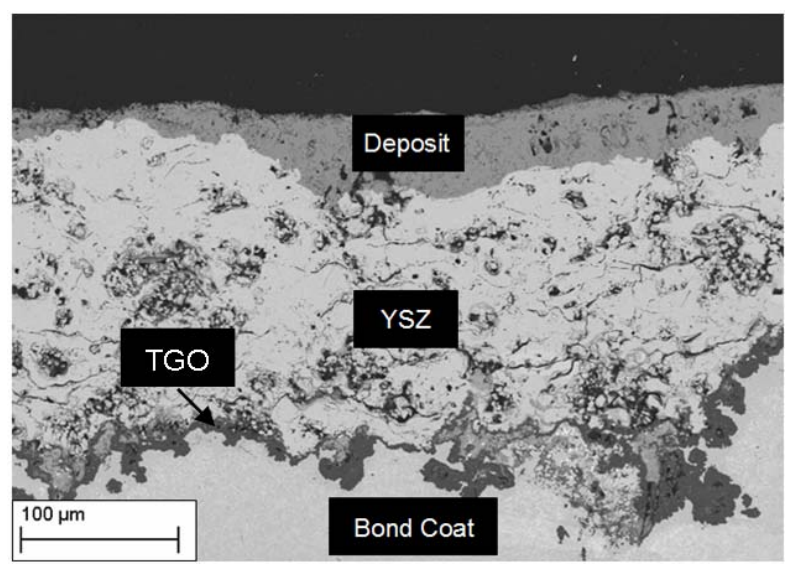

Figure 15 Cross-section SEM image of black deposit

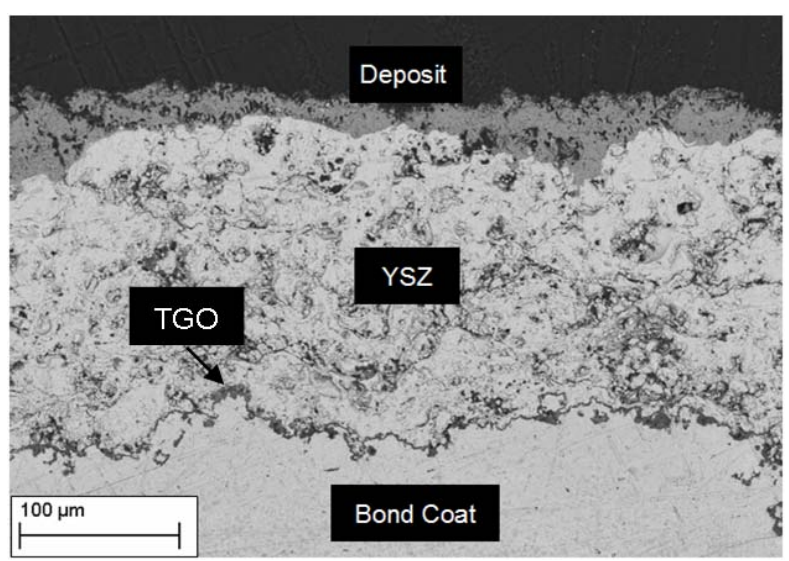

Figure 16 Cross-section SEM image of light brown deposit covered TBC 


\section{$\underline{\text { X-Ray Diffraction }}$}

From the EDS analyses, various elements have been confirmed. It is our interest to know the correct phases of the primary contaminant present in this system, iron. XRD has been conducted at four different positions on the pressure side vane surface, covering both light and dark coloured deposits. Figure 19 shows the XRD spectra of black, red, light brown, and dark brown colour deposit surfaces. Since the deposits layers are generally thick (greater than $30 \mu \mathrm{m}$ in most surfaces) the XRD could only reveal the elemental phases near the surface. A mixture of hematite $\left(\mathrm{Fe}_{2} \mathrm{O}_{3}\right)$ and magnetite $\left(\mathrm{Fe}_{3} \mathrm{O}_{4}\right)$ phases have been identified.

In order to understand the formation of these phases it is necessary to consider the thermodynamic stability of the various iron oxide phases under typical GT operating conditions, specifically with respect to temperature and oxygen partial pressure. The air stream inside the combustion chamber experiences temperatures at over $2000^{\circ} \mathrm{C}$ and most $\mathrm{Fe}$ containing impurities are in the form of liquid phase. Once the hot gas stream exits the combustion chamber, it is then cooled to approximately $1160^{\circ} \mathrm{C}$ just before entering the first turbine stage (TIT). The combustion gas is then mixed with internal cooling air guided from compressor stages, resulting in an oxygen partial pressure of 0.96 atm. The $\mathrm{Fe}_{2} \mathrm{O}_{3} / \mathrm{Fe}_{3} \mathrm{O}_{4}$ pressure-temperature phase diagram adapted from Chiang et al. (Figure 20) [9] was used to predict the phase changes. Through following the cooling curve at a constant oxygen partial pressure $(1 \mathrm{~atm})$, magnetite is the first phase to fully solidify at $1590^{\circ} \mathrm{C}$. Then at $1365^{\circ} \mathrm{C}$, the hematite phase solidifies and co-exists with magnetite.
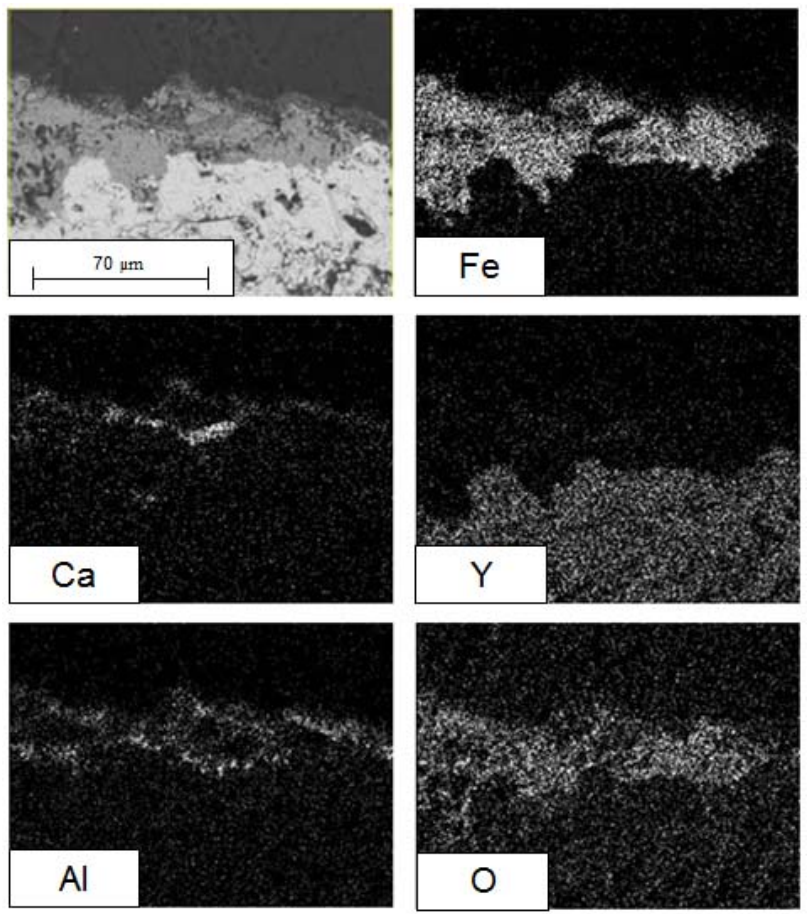

Figure 17 EDS mapping on the cross-section of light brown colour deposit site
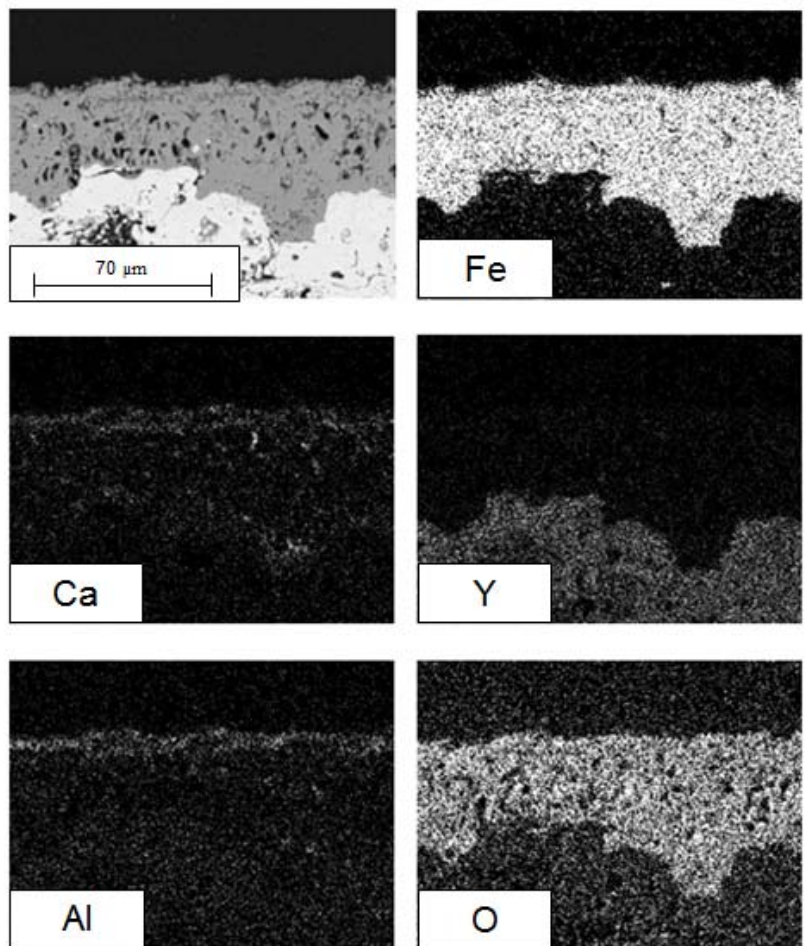

Figure 18 EDS mapping on the cross-section of dark brown colour deposit site

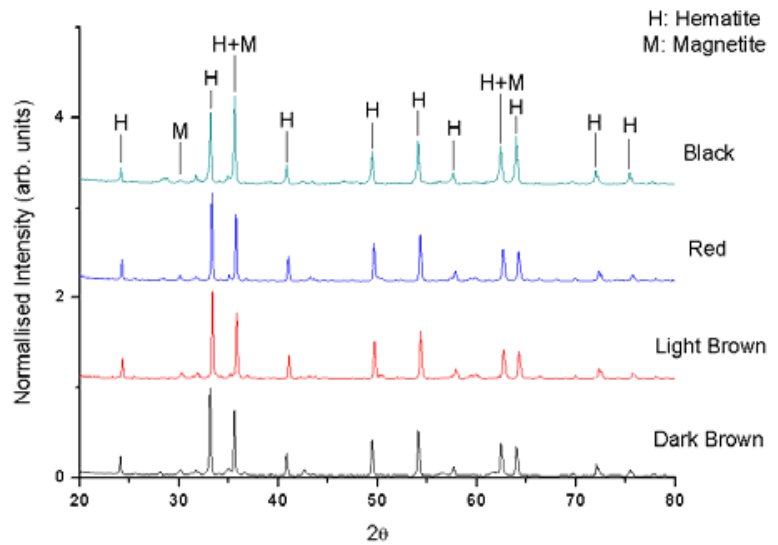

Figure 19 XRD traces of black, red, light brown, dark brown colour deposit surfaces 


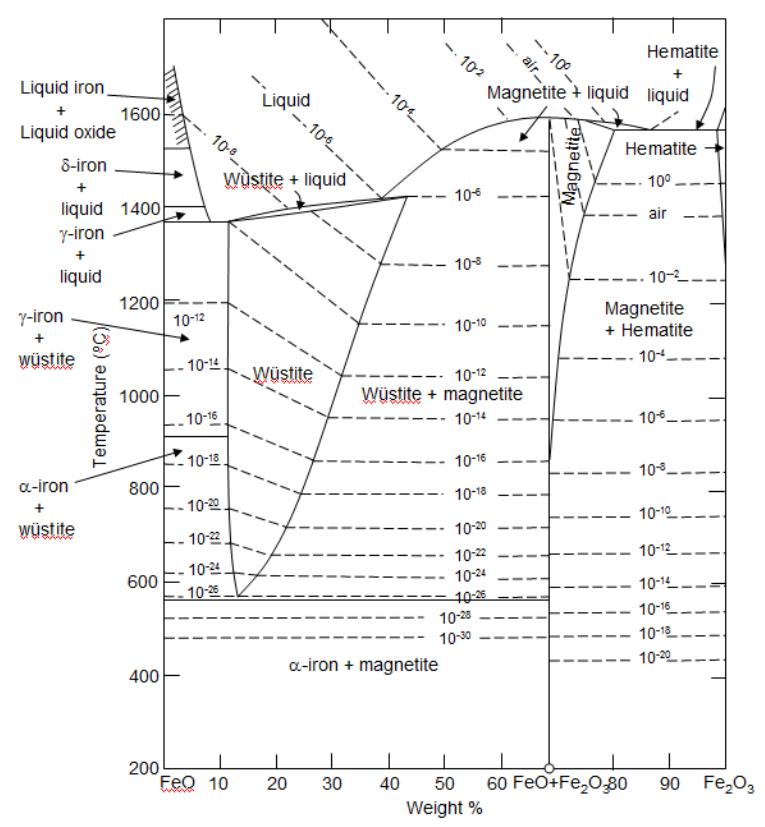

Figure $20 \mathrm{Fe}_{2} \mathrm{O}_{3} / \mathrm{Fe}_{3} \mathrm{O}_{4}$ pressure-temperature phase diagram [9]

\section{$\underline{\text { Temperature Profile }}$}

Cross-sectional and surface SEM analyses on the deposits reveal their microscopic features. At this point, the surface discolouration can be categorized into darker colour and lighter colour deposit groups based on the explicit microscopic features. Darker deposits include black and dark brown where as lighter deposits include red and light brown colours. Flagstone-like plates were only observed on the darker deposit surfaces whereas granular surfaces were mostly observed from lighter deposits. Evidence of sintering is observed in the darker deposit layers but not on the lighter deposits suggesting that the darker colour deposit covered regions experience higher temperatures for longer. This is in agreement with the observations of TGO thicknesses.

From the visual inspection, darker deposits (black and dark brown) were normally found near the pressure side leading edge and trailing edge of the vanes observed. However, in some cases, black deposits were also observed on the pressure side face such as Vane $\mathrm{C}$ which had coating spallation at the pressure side leading edge. The pressure side leading edge and trailing edge of the nozzle guide vanes are the potential sites for coating spallation. XRD analyses at the surface of the deposits across the pressure side have discovered co-existence of magnetite and hematite phases. The $\mathrm{Fe}_{2} \mathrm{O}_{3} / \mathrm{Fe}_{3} \mathrm{O}_{4}$ pressure-temperature phase diagram adapted from Chiang et al. [9] (Figure 20) is used to correlate the range of $\mathrm{TBC}$ surface temperature. The predicted TBC surface temperature in these regions could be reaching as hot as $1365^{\circ} \mathrm{C}$.

\section{Conclusion and Future Work}

Fe-rich chemical deposits from land-based CCGTs have been characterised. In contrast to CMAS, (the main chemical contamination experienced in aerospace applications) these iron oxides neither penetrate through the TBC nor dissolve yttrium content from the YSZ. There is no direct evidence that iron oxide deposits would lead to early coating failure of the TBCs; however, the surface discolouration has a direct relationship with important TBC surface conditions such as temperature and oxygen partial pressure. Regions covered by dark colour deposits are generally hotter than regions covered by light colour deposits. Crosssectional SEM analysis has revealed a sintering effect and rapid TGO growth under the dark colour deposits. Surface images reveal flagstone-like plate and granular surface configurations with the former correspond to hot surface and later correspond to cool surface. XRD analyses have identified hematite and magnetite to be the primary contaminants. Further work is ongoing to fully quantify the surface phases and their relative stability with respect to temperature and $\mathrm{pO}_{2}$.

\section{Acknowledgements}

The authors would like to acknowledge Dr. Jonathan Wells for valuable discussions and technical support as well as RWE group for the research funding.

\section{References}

1. S. Bose, High Temperature Coatings, Butterworth-Heinemann, 2007

2. Thermochemical interaction of thermal barrier coatings with molten CMAS deposits, Stephan Kramer, James Yang, Carlos G. Levi, and Curtis A. Johnson. J. Am. Ceram. Soc., 89 [10] $3167-$ $3175(2006)$

3. Role of environmental deposits and operating surface temperature in spallation of air plasma sprayed thermal barrier coatings, Marcus P. Borom, Curtis A. Johnson, and Louis A. Peluso. Surface and Coating Technology 86-87 (1996) 116-126.

4. F. H. Stott, G. C. Wood, Mater. Sci. Eng. A87, 267 (1987)

5. M. J. Stiger, N. M. Yanar, M. G. Topping, F. S. Pettit, G. H. Meier, Z. Metallkd. 90, 1069 (1999)

6. F. H. Stott, D. J. de Wet and R. Taylor, in F. H. Froes et al. (eds.), The Effect of Molten Silicate Deposits on the Stability of Thermal barrier Coatings for Turbine Applications at Very High Temperatures, Advances in Synthesis and Processes, SAMPE, 3, 1992, M92-101.

7. F. H. Stott, D. J. Wet, R. Taylor. Degradation of thermal-barrier coatings at very high temperatures, MRS Bulletin. Vol 19. no. 10. pp. 46-49. 1994.

8. D. J. de Wet, R. Taylor, and F. H. Stott, Corrosion mechanisms of $\mathrm{ZrO} 2-\mathrm{Y} 2 \mathrm{O} 3$ thermal barrier coating in the presence of molten Middle-east sand. Journal of Physics. IV, 3 [C9] 655-663 (1993).

9. YM Chiang, S. Birnie III and W. D. Kingery, Physical Ceramics, Principles for Ceramic Science and Engineering, John Wiley \& Sons, Inc., Singapore, 1997 